\title{
Song plasticity over time and vocal learning in clay-colored thrushes
}

\author{
Luis E. Vargas-Castro ${ }^{1,2} \cdot$ Natalie V. Sánchez ${ }^{1}$ - Gilbert Barrantes ${ }^{1}$
}

Received: 24 September 2014/Revised: 11 May 2015/Accepted: 8 June 2015/Published online: 27 June 2015

(C) Springer-Verlag Berlin Heidelberg 2015

\begin{abstract}
Songbirds have been traditionally classified into close-ended or open-ended learning species according to the length of the sensitive period during which birds are able to memorize new vocalizations. Closed-ended learners are generally not capable of changing their song after the first year of life, while open-ended learners show song plasticity as adults. A few Turdus species have been suggested to be open-ended learners, but no long-term study has been conducted to investigate their song plasticity over time. We analyzed the songs of clay-colored thrushes, $T$. grayi, over four successive breeding seasons to assess song plasticity in their syllable repertoires within and between breeding seasons. A total of 16,262 syllables were classified through visual inspection of spectrograms and multidimensional scaling analysis based on spectrogram correlations. On average, $563 \pm 153$ (SD) syllables per male per breeding season were analyzed. Male repertoire size was 9-20 syllable types. Males were capable of modifying their syllable repertoire between the initial and final periods of the breeding season. Song plasticity within breeding seasons may be associated with imitation between neighboring males, suggesting song learning in males that were $\geq 2$ years old. This short-term plasticity is not enough, however, to explain the high proportion of change (mean $=65 \%$ syllable types) in repertoire composition between breeding seasons in adult males. Song plasticity resulting from annual changes in repertoire composition
\end{abstract}

Luis E. Vargas-Castro

luis@bio.miami.edu

1 Escuela de Biología, Universidad de Costa Rica, 2060 San Pedro, San José, Costa Rica

2 Present Address: Department of Biology, University of Miami, Coral Gables, FL 33146, USA could be explained by open-ended learning, but another mechanism, extended memory and re-expression, could also explain long-term plasticity. Experimental studies controlling the acoustic environment are needed to determine which mechanism is responsible for such a high level of song plasticity.

Keywords Open-ended learning - Syllable repertoire · Behavioral plasticity $\cdot$ Repertoire size .

Song re-expression $\cdot$ Turdus

\section{Introduction}

The capacity to learn songs or other vocalizations from social interactions has been observed in three orders of birds: Psittaciformes (parrots), Apodiformes (hummingbirds), and Passeriformes (perching birds) (Baptista and Schuchmann 1990; Gaunt et al. 1994; Farabaugh and Dooling 1996; Araya-Salas and Wright 2013). The order Passeriformes contains the suboscines and oscines. In general, the former do not show vocal learning, although exceptions such as the three-wattled bird Procnias tricarunculata have been suggested (Saranathan et al. 2007). The oscines, or songbirds, learn their songs through imitation of adult conspecifics (Marler 1970). Usually, only males sing, with the purpose of attracting mates and defending their territories during the breeding season (Krebs et al. 1978; McGregor and Krebs 1982; Catchpole and Slater 2008).

The song-learning process in oscines involves two main phases: memorization and rehearsal (Kroodsma 1982; Brenowitz and Beecher 2005; Sung and Park 2005; Brainard and Doupe 2013). The memorization phase constitutes a sensitive period for learning conspecific songs (Marler 
and Peters 1982; Beecher and Burt 2004), while during the rehearsal phase, birds adjust their singing output through auditory feedback in order to match the songs that were previously memorized (Brenowitz and Beecher 2005; Sung and Park 2005; Brainard and Doupe 2013). Interspecific variation in the length of these phases during the songlearning process has been used to classify songbirds into closed-ended and open-ended learning species. Songs are highly variable in acoustic structure during the rehearsal phase, but this variability decreases over time until the bird only sings stereotyped songs, a process termed crystallization (Marler 1970). Crystallization usually occurs during the first year of life, and closed learning species are not able to learn new songs after this point (Marler and Peters 1982; Catchpole and Slater 2008). For this reason, closedended learners are also called age-limited learners. In contrast, song learning continues after singing crystallized song in open-ended learners (Brenowitz and Beecher 2005). Some oscines have been considered open-ended learners because their songs change over the years (Espmark and Lampe 1993; Mountjoy and Lemon 1995; Nottebohm 2004), and adult song plasticity is compatible with open-ended learning. Nonetheless, this classification represents two extremes of song-learning strategies, and it has been suggested that the difference between closed-ended and open-ended learning species can be seen as a quantitative difference in the amount of song plasticity rather than a qualitative difference regarding the presence or absence of this plasticity (Brenowitz and Beecher 2005).

Repertoires, which are the set of different song types or syllable types that a bird sings, are influenced by social interactions since different repertoire components may be originated, dispersed, extinguished, or modified within populations in a very dynamic way over time (Lynch 1996; Payne 1996). Thus, males of some species change their repertoire composition within a breeding season (Espmark and Lampe 1993; Nicholson et al. 2007) or between breeding seasons (Sorjonen 1987; Leitner et al. 2001), in some cases, adding new song components over time (Espmark and Lampe 1993).

Common blackbirds Turdus merula and American robins T. migratorius change their song repertoire as adults, at least during their first breeding season (Rassmussen and Dabelsteen 2002; Johnson 2006). Rassmussen and Dabelsteen (2002) observed changes in the slopes of cumulative curves of new motif types in common blackbirds and suggested that new types were learnt during the study. However, these changes occurred within a short sampling period (1-9 days) and could have been the result of natural patterns of how different motif types are used (Rassmussen and Dabelsteen 2002). Johnson (2006) conducted hand-rearing experiments with American robins and observed that some males imitated song elements of other males from the experiment. Since these individuals did not begin to sing until they were sexually mature, he showed that American robins are capable of learning song components during the first breeding season. In the field, Johnson (2006) also observed that two males gradually transformed the acoustic structure of one element of their repertoires during a breeding season. In one of these cases, this modification made the element more similar to one found in the repertoires of three other males from the same population. Repertoire changes during the first breeding season have been reported in other songbirds, usually leading to a higher proportion of repertoire sharing with territorial neighbors (DeWolfe et al. 1989; Payne and Payne 1997; Nordby et al. 2001; Kipper and Kiefer 2010). These changes typically result from dropping or adding repertoire components, but gradual transformation of song components is seldom reported, perhaps because it is rare in nature or difficult to detect. Johnson (2006) was not able to distinguish whether or not this capacity was limited to the first breeding season in wild American robins, since their age was unknown.

These studies suggest there could be song plasticity and open-ended learning in Turdus, but we lack long-term investigations following specific individuals between breeding seasons to determine to what extent this capacity is limited by age. In this study, we analyzed the song plasticity of clay-colored thrushes $T$. grayi over time. The objectives were to determine if repertoire size and composition change: (a) between successive breeding seasons in 1-4 year old males and (b) within a breeding season in 2-year-old males. We also discuss the implications of song plasticity in relation to vocal learning focusing on the songbirds (suborder Passeri).

\section{Clay-colored thrushes and their songs}

The clay-colored thrush is an open-habitat songbird, common in gardens, pastures, and urban areas, distributed from southern Texas, USA, to northern Colombia (Stiles and Skutch 1989; Clement 2001). Clay-colored thrushes, like other member of the Turdidae family, are well known for their melodious and skillful vocalizations. During the breeding season, males sing frequently throughout the day to defend a small territory where females build a nest, in trees or on human-made structures.

The songs of clay-colored thrushes are sequences composed of from one up to more than 100 syllables (Fig. 1), and successive songs have different sets of syllable types. Males may share a small proportion of their syllable repertoires with other males of the same locality (VargasCastro et al. 2012), but whole song sharing has not been observed; thus, syllables appear to be the unit of imitation during vocal learning. Therefore, it is more appropriate to classify syllable types instead of whole songs in order to measure syllable repertoire size. This approach has been 
Fig. 1 Spectrograms of the songs of two male clay-colored thrushes during two successive breeding seasons (2009-2010). The upper two spectrograms correspond to one individual, while the lower two correspond to another male. These songs are composed of $15,11,11$, and 8 syllables, respectively.

Syllables labeled with the same letter (within males) represent syllable types that were present in the repertoires of both years (color figure online)

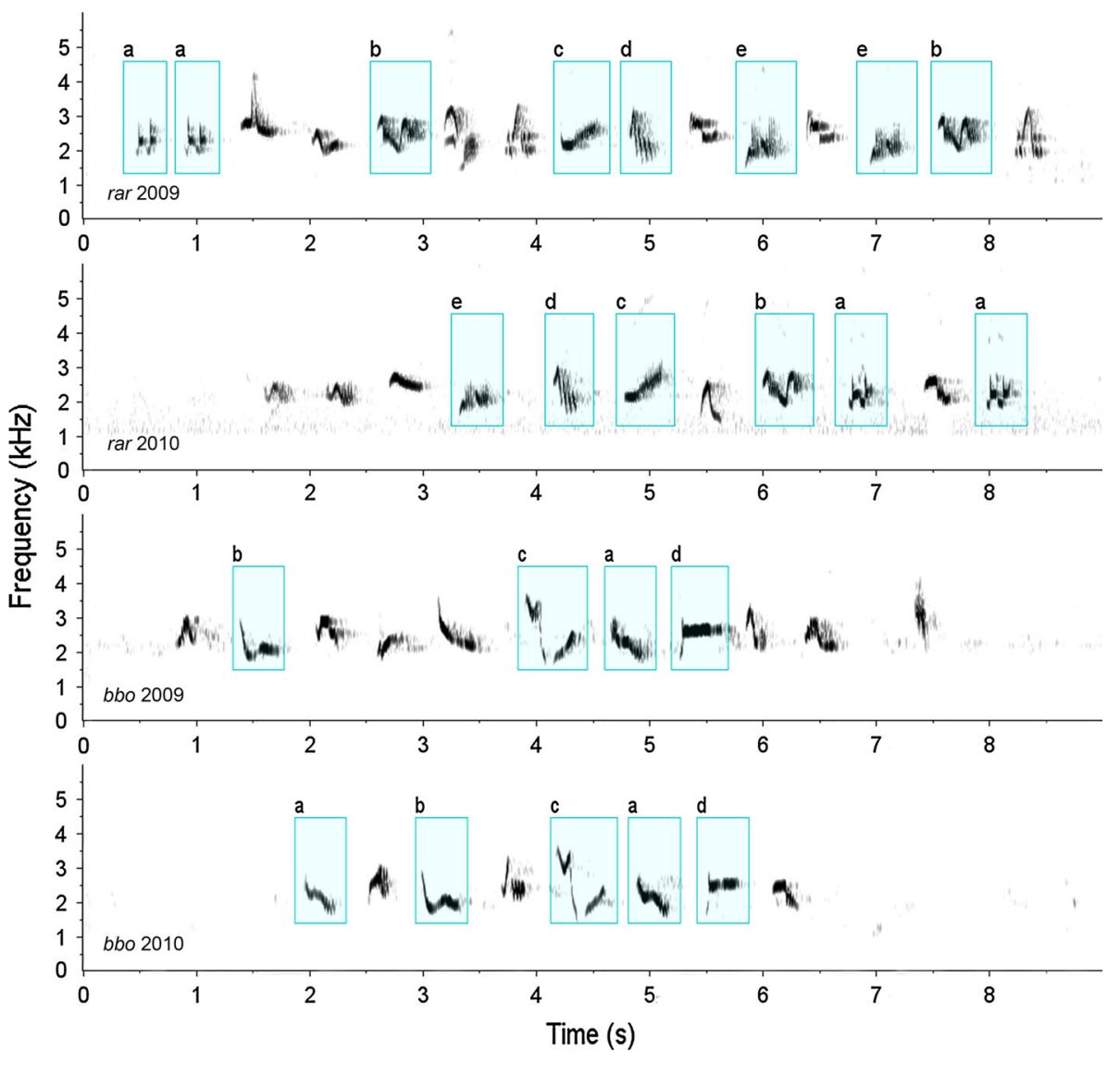

Materials and methods

used in other species with a similar singing style (Gil and Slater 2000). Hereafter, repertoire refers to the set of different syllable types that constitute the songs of a given male in a given period of time.

Two syllable categories are found in the songs of Turdus thrushes: broadcast syllables (whistles) and soft syllables (Grabowski 1979; Rassmussen and Dabelsteen 2002; Johnson 2006; Vargas-Castro 2015). In general, broadcast syllables have higher amplitude and simple acoustic structure compared with soft syllables. During spontaneous song bouts, clay-colored thrushes predominantly use broadcast syllables (97\% of total syllables) and only a few soft syllables may be embedded in these songs (Vargas-Castro et al. 2012). In other songbird species, soft songs are mainly used in courtship displays or aggressive signaling, or both, during close range interactions (Dabelsteen et al. 1998; Searcy and Beecher 2009). Clay-colored thrushes also produce soft song in courtship displays and even during copulation (LEV personal observation), but their role in aggressive interactions remains to be investigated. Since broadcast syllables are more frequent in spontaneous songs, have higher amplitude and a relatively simple acoustic structure, facilitating both their sampling and classification, we only analyzed broadcast syllables in the present study. Henceforth, 'syllables' refers to broadcast syllables.
The study was conducted at the main campus of the University of Costa Rica (UCR), in San Pedro de Montes de Oca district, San Jose Province, Costa Rica $\left(09^{\circ} 56^{\prime} 11^{\prime \prime} \mathrm{N}, 84^{\circ} 02^{\prime} 57^{\prime \prime} \mathrm{W} ; 1200 \mathrm{~m}\right.$ asl). The campus is composed of various buildings located among gardens, open fields, scattered vegetation, and two small patches of secondary forest. The clay-colored thrush breeding season extends from March to June at this site. We conducted the study during four breeding seasons: 2008-2011. We analyzed data of eight color banded males. Individuals were banded by LEV or NVS specifically for this investigation; more than 70 individuals (both sexes) were banded at the beginning of the study, but most of them were not seen again in the area. As the study site contains one small creek, it is possible that multiple nonresident individuals were captured and marked as they were just passing by to visit this creek. Male territories were separated by variable distances, from 30 to $500 \mathrm{~m}$, and thus, not all males were immediate neighbors.

Since male age was unknown, we assigned a minimum age of 1 year to the adult males captured during 2008. This minimum age method has been used in other longitudinal field studies (Gil et al. 2001; Nicholson et al. 2007). We 
analyzed the songs of three males in four successive years, two males in three successive years, and two other males during two consecutive years. Fluctuation in these numbers is presumably due to predation. One additional male was recorded only during 2009 and was used in the analysis of song plasticity within the breeding season (see below). This research complies with the current laws of Costa Rica.

\section{Song plasticity between successive breeding seasons}

We recorded $\geq 360$ song syllables from each male between March 21 and May 11 in each year. This syllable sample size is comparable with approximately 16 min of effective recording time. The recordings from 2008 used here have also been included in a previous study investigating local repertoire sharing among males (Vargas-Castro et al. 2012). On average, repertoires are composed of 13 (range 10-17) syllable types, and even though most syllable types are unique to particular males, $28 \pm 15 \%$ (mean \pm SD) syllable types of their repertoires may be shared with other males.

Clay-colored thrushes sing with immediate variety (successive syllables are different) (Fig. 1). Cumulative curves of new syllable types showed that full syllable repertoires are detected after classifying 350 syllables (Vargas-Castro et al. 2012). For one male in 2008, we only recorded 272 syllables, but since the cumulative curve quickly approached an asymptote for this male, we were confident that we detected his full repertoire.

\section{Song plasticity within a breeding season}

In 2009, the songs of six adult males ( $\geq 2$ years old) were studied during a longer time period to examine if there was repertoire plasticity throughout the breeding season. For this analysis, we used the first recordings available, starting on March 21, to classify $>400$ syllables and assess repertoire composition for each male (Fig. 2). Then, we also analyzed songs recorded after April 26 to classify $>400$ additional syllables and re-assess repertoire composition. Thus, the time interval of the recordings used during this breeding season extended from March 21 to May 31 and was divided into two periods of approximately 5 weeks each. We examined repertoire composition in both periods to register possible modifications such as addition or deletion of syllable types during the breeding season.

\section{Song recordings}

We analyzed a total of 16,263 syllables, 12,945 of which were used in the analysis of song plasticity between breeding seasons. On average, $563 \pm 153$ (SD) syllables per male per breeding season were classified. The song

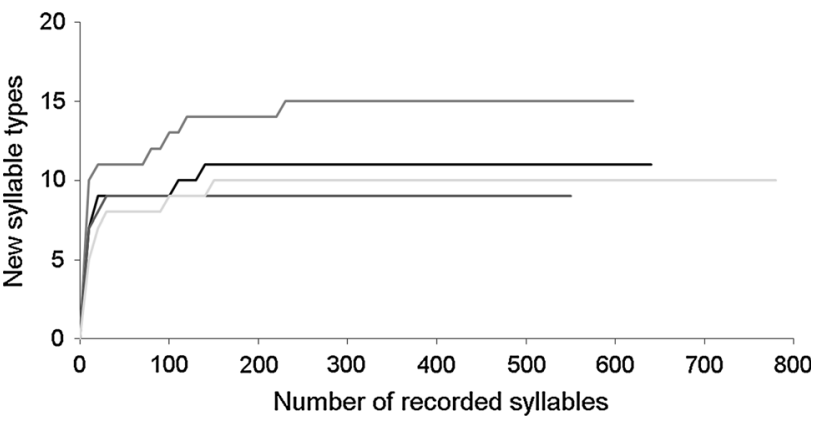

Fig. 2 Examples of cumulative curves of repertoire size according to the number of syllables recorded in the songs of clay-colored thrushes during the initial period of the breeding season in 2009. In these four males, syllable additions were observed during the final period of the same breeding season (see "Results")

plasticity analysis within the 2009 season included 3318 additional syllables that were recorded during the final period of the breeding season, averaging $553 \pm 122$ (SD) syllables per male. All songs analyzed correspond to spontaneous singing activity. Songs were recorded mainly between 0400 and 0600 hours, but we also used recordings from other time periods. There were no relevant daily differences in repertoire composition.

In 2008, we used a Sony M-635VK tape recorder and later digitized the recordings using Adobe Audition 1.0 (Adobe Systems, Inc., San Jose, CA, USA) to produce uncompressed audio files. From 2009 to 2011, we used Olympus LS-10 or Marantz PMD661 digital recorders. In all years, we used a Sennheiser ME66/K6 shotgun microphone to record the songs. All recordings were stored as wav files ( $44.1 \mathrm{kHz}$ sample rate, 16 bit resolution).

\section{Syllable classification and analysis}

We analyzed spectrograms of the recordings using Raven Pro 1.4 (Cornell Lab of Ornithology, Ithaca, NY, USA). We generated spectrograms with Hann window type, 700 samples and a discrete Fourier transform (DFT) size of 2048 samples with a temporal overlap of $75 \%$. A bandlimited energy detector (Charif et al. 2010) was used to automatically detect clay-colored thrush song in the recordings.

Spectrograms were visually inspected to identify the syllable types of each male's repertoire. Each syllable type is observed as a figure with a specific pattern in the frequency-time domains of the spectrogram (Fig. 1). A similar procedure has been used in other studies to classify bird vocalizations (Molles and Vehrencamp 1999; Rassmussen and Dabelsteen 2002; Nicholson et al. 2007; Vargas-Castro et al. 2012). All syllables were inspected by two independent observers to determine which syllables were present in more than one breeding season. Inter-observer agreement 
was almost perfect, reaching $99.7 \%$ of all possible comparisons (20/6091). The few cases of disagreement were reevaluated until a general consensus was reached. The validity of our visual classification was re-examined using multidimensional scaling analysis (MDS) (see below) (Nowicki and Nelson 1990).

Song plasticity between breeding seasons was measured as the proportion of change in the repertoire of each male between years using the Sørensen-Dice index: $1-\left(2 N_{\mathrm{s}} /\right.$ $\left(R_{1}+R_{2}\right)$ ); where $N_{\mathrm{s}}$ is the number of syllable types present in the repertoires of two successive breeding seasons, while $R_{1}$ and $R_{2}$ constitute repertoire size in each of these breeding seasons. The negative part of this formula has been used to calculate the proportion of shared song components between two males (McGregor and Krebs 1982; Kipper et al. 2004; Eriksen et al. 2011). This index gives values between 0 and 1 , with 0 indicating identical repertoires and 1 indicating full replacement of the syllable repertoire.

\section{Spectrogram correlation and multidimensional scaling analysis (MDS)}

We selected three examples of each syllable type, with high recording quality, from the repertoires of each male and calculated spectrogram correlation values between all the sound files using Raven Pro 1.4. Spectrogram correlations measure the maximum pixel by pixel similarity between two spectrograms (Cramer 2013). We used spectrograms with Hann window type, 700 samples, and a DFT size of 1024 samples with a temporal overlap of $50 \%$. The 'normalize' and 'linear power' options were selected, and a $1000-4500 \mathrm{~Hz}$ band-pass filter was applied to eliminate background noise interference outside of the songs' frequency range. The correlation square matrix, of dimensions equivalent to the number of sound files, was imported into $\mathrm{R}$ version 2.14.0 (R Development Core Team 2012). The value of each cell was subtracted from 1 to convert it into a dissimilarity matrix. A nonmetric MDS was conducted using the MASS package in R, solving for two dimensions. This technique allowed us to evaluate the grouping or dispersion of the syllables in a bi-dimensional geometric space according to their acoustic structure differences. The procedure was conducted independently for each male in each year, and to reevaluate the few cases where there was disagreement between observers while classifying syllable types.

\section{Statistical analysis}

We analyzed repertoire size variation within males according to age using a Friedman test (Zar 1996). Data on five males during three breeding seasons (2008-2010) were used to obtain a balanced model. In addition, we conducted a Pearson correlation test between the number of breeding seasons that males were sampled and their accumulated repertoire size to determine if there was an association between the two variables. All tests were two-tailed and conducted using R version 2.14.0 (R Development Core Team 2012).

\section{Results}

Figure 3 shows broad agreement between the visual classification of syllable types and the grouping of syllables according to the MDS. For example, syllables visually classified as type ' $o$ ' due to their similar acoustic structure were grouped together in the same area of the bi-dimensional geometric space produced by the MDS analysis (see Fig. 3, upper diagram bottom center). Syllable examples from different breeding seasons that were visually classified as the same syllable type were also grouped together in the MDS analysis diagrams (see syllables ' $e$ ' from 2010 to 2011, top right corner of lower diagram in Fig. 3). In a few cases, however, examples of syllables visually classified as different types were not completely separated in the diagram. In these cases, most of the energy of the syllables was concentrated in the same frequency band, which resulted in high spectrogram correlation values although their frequency-temporal pattern was clearly different. For example, see syllable $p$ grouping with syllable $j$ in Fig. 3 (upper diagram, top center).

\section{Song plasticity between successive breeding seasons}

In four breeding seasons, 12,945 syllables were classified into 219 syllable types. Average male repertoire size was 13 (range 9-20) syllable types. Although there were small variations in male repertoire size as age increased, repertoire size was similar over the years (Friedman test, $X_{(2)}^{2}=0.88, P=0.64$ ) (see Fig. 4). However, repertoire composition did change with an average of $65 \%$ (range $41-95 \%, N=7$ males) of the syllable repertoire changing between 1 year and the next. Figure 5 shows that $73 \%$ of the syllables composing the repertoires changed, on average, between the first and second year. Then, an average of $62 \%$ of the repertoires changed between the second and third year. Finally, between years three and four, $49 \%$ of the syllable repertories changed, showing that even males that were $\geq 4$ years old showed considerable inter-annual changes in repertoire composition. However, this pattern of decreasing proportion in repertoire change between successive breeding seasons was not statistically significant (Kruskal-Wallis test, $X_{(2)}^{2}=1.26, P=0.53$ ).

These annual changes resulted from the inclusion of new syllable types that replaced other ones. By adding up each 

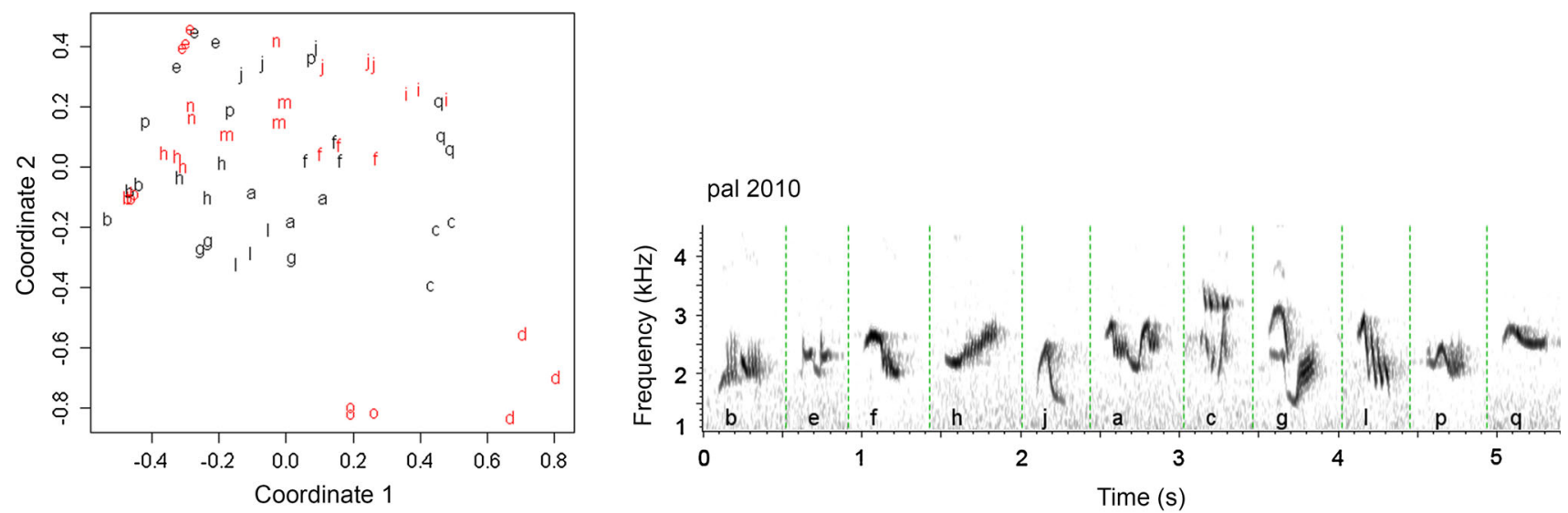

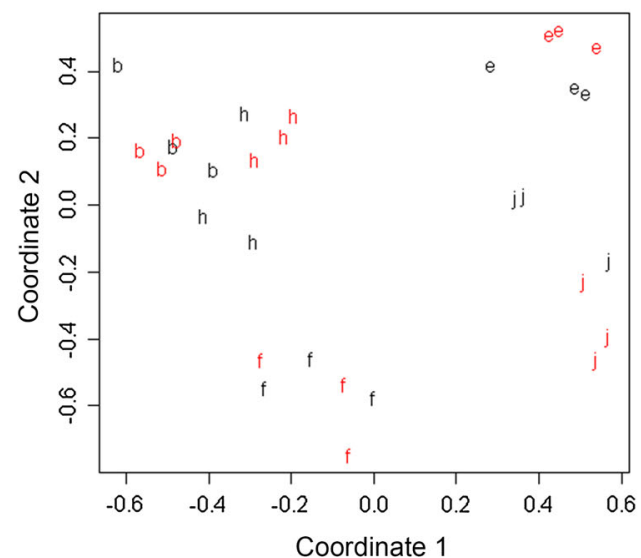

Fig. 3 MDS analysis diagrams (left) of the combined repertoires of one male in two successive breeding seasons. Each letter denotes a syllable type in 2010 (black) and 2011 (red). The upper diagram shows full repertoires, while the lower diagram only includes the five

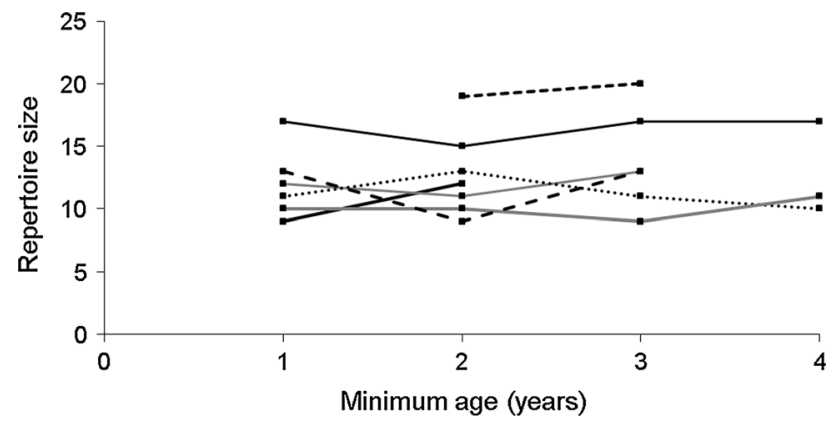

Fig. 4 Syllable repertoire size according to minimum age in the songs of clay-colored thrushes during the 2008-2011 breeding seasons. Each line corresponds to one male

new syllable type from all the breeding seasons each male was sampled, we were able to detect an accumulated repertoire through successive breeding seasons. Figure 6 shows that the more breeding seasons a male was sampled, the larger its accumulated repertoire size was $(r=0.74$, $N=8, P=0.036)$.

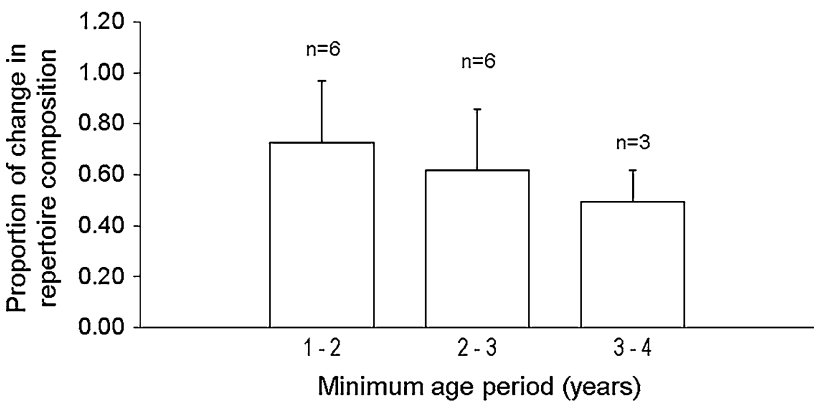

Fig. 5 Proportion of change in the syllable repertoire composition of clay-colored thrushes according to change in minimum age during the 2008-2011 breeding seasons. Means + SD are shown

Few syllable types remained in the repertoires during three or four consecutive breeding seasons. On average, the syllables that remained for three seasons, or four seasons, constituted $10 \%$ (range $0-23 \%, n=5$ ) and $5 \%$ (range $0-10 \%, n=3$ ) of the accumulated repertoires, respectively. Also, two syllable types of one male were used intermittently; after being present in the repertoire of a 


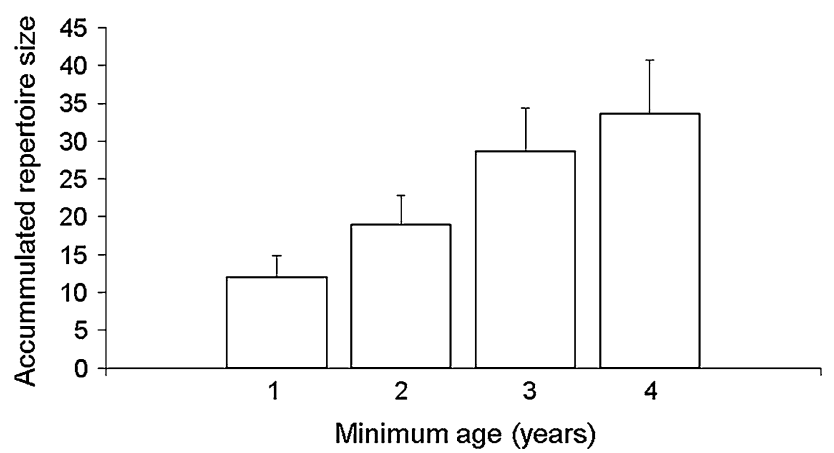

Fig. 6 Mean accumulated repertoire size of syllable types in male clay-colored thrushes over four breeding seasons (2008-2011)

given year, they were absent the following year and reappeared again in the repertoire 2 or 3 years later.

\section{Song plasticity within a breeding season}

We observed modifications in the repertoire composition of four males in which 1-4 syllable types were added between the initial and final periods of the breeding season. The proportion of use of these additions was relatively low; each added syllable represented less than $2 \%$ of the total syllables used during the final period by a given male. One exception was a syllable addition that reached $8 \%$ of the syllables sung in the final period. For comparison, the mean proportion of use of syllable types also was $8 \%$ of the total syllables used by one male in a given period.

Moreover, it is possible that one of these additions resulted from the gradual modification of one syllable type into another (see Fig. 7). As shown in Fig. 8 for this case, the new version of the syllable sung by one male in 2009 showed high acoustic similarity to syllables present in the repertoires of other three males during the same or previous breeding seasons. In 2010, the same male used a similar syllable again, but we are not certain if the 2010 version originated from the one added in 2009, although it seems possible.

\section{Discussion}

\section{Song plasticity between successive breeding seasons}

Although repertoire size in adult males did not change over the breeding seasons, substantial plasticity in repertoire composition was observed in clay-colored thrush males that were $\geq 4$ years old. The use and replacement of syllable types were very dynamic between breeding seasons. Inter-annual changes in repertoire composition showed that over the course of their lifetime, each male will express more syllable types than those it uses during a single

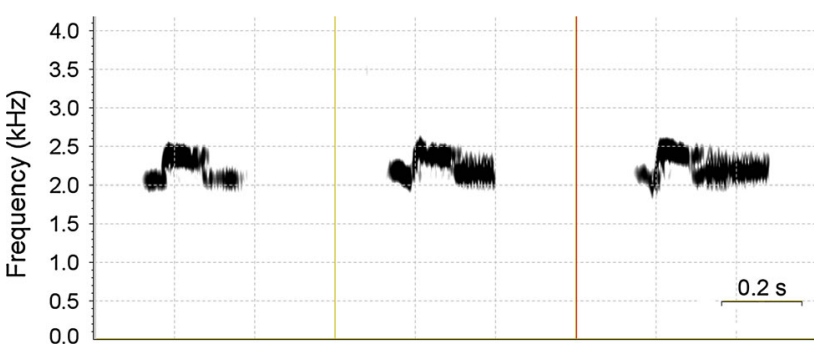

Fig. 7 New syllable added to the repertoire of one male ( $\geq 2$ years old) that may have resulted from the gradual transformation of one syllable type into another. The variation in acoustic structure occurred between the initial (left) and final (right) periods of the breeding season

breeding season. This accumulated (or lifetime) repertoire could result from two different mechanisms: (a) extended memory and re-expression or (b) open-ended learning (Nottebohm 2004; Hough et al. 2000; Franco and Slabbekoorn 2009).

In the first case, extended memory and re-expression, an individual memorizes more song components than those that are used during the first breeding season. The sensitive learning phase in which songs are memorized is variable within songbird species, but in a number of species is limited to the first year of life (Brenowitz and Beecher 2005). Song components that were learnt during the sensitive phase but that are not part of the first breeding season repertoire may be stored in the memory and re-expressed in subsequent breeding seasons (Hough et al. 2000). Playback experiments have shown that it is possible to reactivate song components that are not spontaneously sung but still remain in the memory (common starlings Sturnus vulgaris in Chaiken et al. 1994; common nightingales Luscinia megarhynchos in Geberzahn et al. 2002; great tits Parus major in Franco and Slabbekoorn 2009). It is possible that clay-colored thrushes learn a number of syllables during the memorization phase and later sing only a subset of the total repertoire that was learnt. Thus, the extended memory and re-expression mechanism may explain the song plasticity observed between breeding seasons and implies that the size of their lifetime repertoire (accumulated) is predetermined during the memorization phase, and no subsequent learning is required.

Using a subset of syllables from a larger repertoire is comparable with the selective attrition process described in white-crowned sparrows Zonotrichia leucophrys (DeWolfe et al. 1989) and other sparrows (swamp sparrows Melospiza georgiana in Marler and Peters 1981; field sparrows Spizella pusilla in Nelson 1992). White-crowned male sparrows sing the same single song type every year, but at the beginning of the breeding season, up to 4 years old, temporarily re-express song types that had been dropped during the rehearsal phase of the first year (Hough et al. 
Fig. 8 Versions of a similar syllable type in four claycolored thrushes. Males rar and pan used this syllable in their repertoires in 2008. Male eco used a similar syllable in 2009. Male $b b o$ acquired a similar syllable during the final period of the 2009 breeding season, possibly by gradually transforming the pattern of another syllable type (see Fig. 7). One syllable used by the later male in 2010 seems to be even more similar to the versions of the other males of the local population

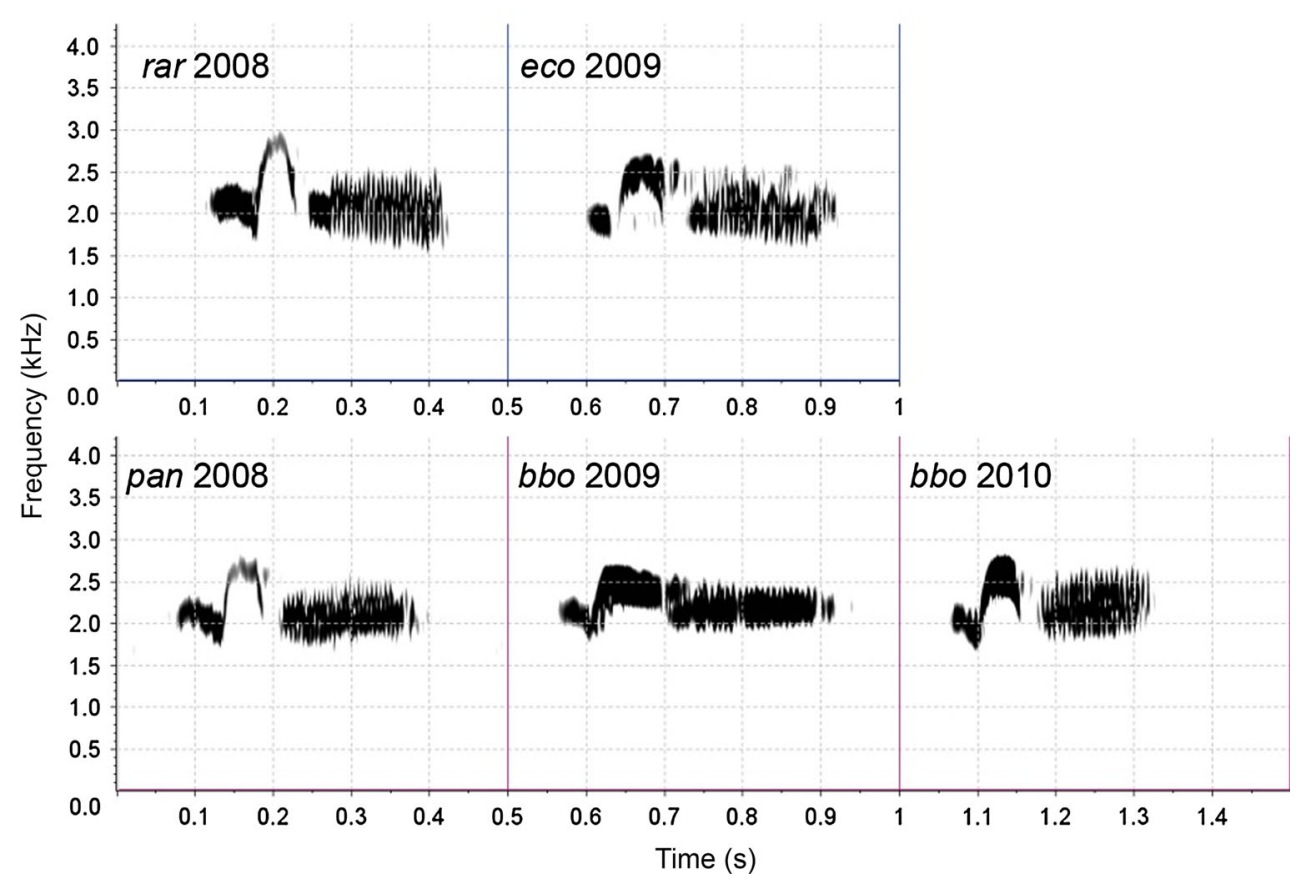

2000). Clay-colored thrush males may be re-expressing syllable types that were previously memorized, but in contrast with white-crowned sparrows, syllable re-expression could be associated with the capacity to change the repertoire composition in successive breeding seasons.

If there is an annual syllable selection from a predetermined repertoire, is it random? Common nightingales modify the repertoire composition between their first and second year to match those songs that are shared by most individuals within the population (Kiefer et al. 2009; Kipper and Kiefer 2010). A similar process could take place in clay-colored thrushes, but more studies are needed to determine if syllable selection is arbitrary or not. We also observed that some syllables remained in the repertoires during four successive breeding seasons. At this point, it is unknown if the permanence of these syllables in the repertoires was favored by certain acoustic structural traits or social interactions.

On the other hand, open-ended learning is another mechanism that could explain song plasticity over the years in the clay-colored thrush. This mechanism requires that the memorization phase remains active during adulthood after singing crystallized song (Brenowitz and Beecher 2005). Chaiken et al. (1994) determined that common starlings have open-ended learning by showing that males of this species are capable of learning new song components up to 20 months old. Other species such as canaries Serinus canarius (Nottebohm et al. 1986), red-winged blackbirds Agelaius phoeniceus (Marler et al. 1972), common nightingales (Todt and Geberzahn 2003), European pied flycatchers Ficedula hypoleuca (Eriksen et al.
2011), and sedge warblers Acrocephalus schoenobaenus (Nicholson et al. 2007) have been considered open-ended learners mainly because changes in their repertoire composition have been observed between breeding seasons. However, it is necessary to control the acoustic environment since birth to determine if the observed song plasticity is due to open-ended learning in adults instead of the extended memory and re-expression mechanism mentioned above. The present study places clay-colored thrushes in the group of songbird species with song plasticity in adult repertoire composition. The observed song plasticity in individuals up to 4 years old or more suggests that this species possesses open-ended learning, but re-expression of syllables learnt during a previous age-limited sensitive phase remains as a possibility.

Accumulation of new syllable types over time opens the possibility of having a larger repertoire size in upcoming breeding seasons. Males with larger repertoires may be preferred by females (Searcy 1992; Lampe and Saetre 1995; Buchanan and Catchpole 1997), whether directly or by association with other traits such as age or territory quality (Howard 1974; Searcy and Andersson 1986). Since repertoire size did not increase as age increased, we suggest that the main function of repertoire size is not female attraction in this species. Also, it appears that neural mechanisms or traits, such as the volume of the high vocal center (HVC) in the brain (Devoogd et al. 1993; Pfaff et al. 2007), may be limiting repertoire size during each breeding season. However, Gil and Gahr (2002) reported that there is no convincing evidence about neuronal costs constraining repertoire size. 


\section{Song plasticity within a breeding season}

We also observed song plasticity during the breeding season. Adult males that were $\geq 2$ years old had the capacity to modify their repertoire composition over the course of the breeding season. This short-term plasticity consisted of the addition of one or a few syllable types that were used with low frequency during the final period. It is possible that the low proportion of use of these syllables made their detection difficult. However, cumulative curves of new syllable types quickly reached asymptotes during the initial period. We also observed the addition of a syllable type that composed more than $7 \%$ of the syllables sung by a male. This frequency of use is similar to the rest of syllable types, and it is unlikely that it was not detected during the initial period by sampling error. Therefore, it is valid to consider that these repertoire modifications represent plasticity in repertoire composition within a breeding season.

Vocal imitation may be associated with song plasticity over the short term in clay-colored thrushes. The high synchrony of dawn choruses during the breeding season (Stutchbury et al. 1998) and the close location of neighbor territories (Dyrcz 1983) suggest that vocal interactions occur under a very dynamic social environment during the breeding season. Moreover, the sedentary habits of this species with high territorial density may increase the chance of imitation between individuals, as observed in other species (Kroodsma et al. 1999). Although it has been observed that males from this population share syllable types with close neighbors (Vargas-Castro et al. 2012), it is uncertain if the syllables added during the final period of the breeding season by the $\geq 2$-year-old males were learnt by imitation. Two of these syllables may have been added through gradual transformation of another syllable, and in one of these cases, the new syllable was a more similar version to that of a syllable present in the repertoire of other males. As mentioned earlier, Johnson (2006) also observed a similar phenomenon in American robins. These observations suggest an association between short-term song plasticity and vocal imitation in Turdus, but this remains to be tested. Laboratory studies under controlled acoustic environments since early life stages and spanning two or more years are needed to further investigate the role of social imitation on the short-term repertoire plasticity of adult thrushes.

Acknowledgments We thank the Oficina de Seguridad y Transito of the University of Costa Rica for providing logistical support. Bill Eberhard, Eric Fuchs, and Bill Searcy made helpful comments on earlier versions of the manuscript. Laura Strickman and Dean Hawthorne helped to configure a sound detector in Raven. Jeff Woodman and Tim Burr provided recording equipment.
Ethical standard All applicable international, national, and/or institutional guidelines for the care and use of animals were followed.

Conflict of interest The authors declare that they have no conflict of interest.

\section{References}

Araya-Salas M, Wright T (2013) Open ended song learning in a hummingbird. Biol Lett 9:20130625

Baptista LF, Schuchmann KL (1990) Song learning in the Anna Hummingbird (Calypte anna). Ethology 84:15-26

Beecher MD, Burt J (2004) The role of social interaction in bird song learning. Curr Dir Psychol Sci 13:224-228

Brainard MS, Doupe AJ (2013) Translating birdsong: songbirds as a model for basic and applied medical research. Annu Rev Neurosci 36:489-517

Brenowitz E, Beecher MD (2005) Song learning in birds: diversity and plasticity, opportunities and challenges. Trends Neurosci 28:127-132

Buchanan KL, Catchpole CK (1997) Female choice in the sedge warbler, Acrocephalus schoenobaenus: multiple cues from song and territory quality. Proc R Soc B 264:521-526

Catchpole CK, Slater PJR (2008) Bird song biological themes and variations, 2nd edn. Cambridge University Press, Cambridge

Chaiken M, Bohner J, Marler P (1994) Repertoire turnover and the timing of song acquisition in European starlings. Behaviour 128:25-39

Charif RA, Waack AM, Strickman AM (2010) Raven Pro 1.4 user's manual. Cornell Lab of Ornithology, Ithaca

Clement P (2001) Thrushes. Princeton University Press, Princeton

Cramer ERA (2013) Measuring consistency: spectrogram cross-correlation versus targeted acoustic parameters. Bioacoustics 22:247-257

Dabelsteen T, McGregor PK, Lampe HM, Langmore NE, Holland J (1998) Quiet song in song birds: an overlooked phenomenon. Bioacoustics 9:89-105

Devoogd TJ, Krebs JR, Healy SD, Purvis A (1993) Relations between song repertoire size and the volume of brain nuclei related to song: comparative evolutionary analyses amongst oscine birds. Proc R Soc B 254:75-82

DeWolfe BB, Baptista LF, Petrinovich L (1989) Song development and territory establishment in Nuttall's white-crowned sparrows. Condor 91:397-407

Dyrcz A (1983) Breeding ecology of the clay-coloured Robin Turdus grayi in lowland Panama. Ibis 125:287-304

Eriksen A, Slagsvold T, Lampe HM (2011) Vocal plasticity—are pied flycatchers, Ficedula hypoleuca, open-ended learners? Ethology 117:188-198

Espmark YO, Lampe HM (1993) Variations in the song of the pied flycatcher within and between breeding seasons. Bioacoustics 5:33-65

Farabaugh SM, Dooling RJ (1996) Acoustic communication in parrots: laboratory and field studies of budgerigars, Melopsittacus undulates. In: Kroodsma DE, Miller EH (eds) Ecology and evolution of acoustic communication in birds. Comstock Publishing Associates, New York, pp 97-117

Franco P, Slabbekoorn H (2009) Repertoire size and composition in great tits: a flexibility test using playbacks. Anim Behav 77:261-269

Gaunt SLL, Baptista LF, Sánchez JE, Hernandez D (1994) Song learning as evidenced from song sharing in two hummingbird species (Colibri coruscans and C. thalassinus). Auk 111:87-103

Geberzahn N, Hultsch H, Todt D (2002) Latent song type memories are accessible through auditory stimulation in a hand-reared songbird. Anim Behav 64:783-790 
Gil D, Gahr M (2002) The honesty of bird song: multiple constraints for multiple traits. Trends Ecol Evol 17:133-141

Gil D, Slater PJB (2000) Song organisation and singing patterns of the willow warbler, Phylloscopus trochilus. Behaviour 137:759-782

Gil D, Cobb JLS, Slater PJB (2001) Song characteristics are age dependent in the willow warbler, Phylloscopus trochilus. Anim Behav 62:689-694

Grabowski GL (1979) Vocalizations of the Rufous-backed thrush (Turdus rufopalliatus) in Guerrero, Mexico. Condor 81:409-416

Hough GE, Nelson DA, Volman SF (2000) Re-expression of songs deleted during vocal development in white-crowned sparrows, Zonotrichia leucophrys. Anim Behav 60:279-287

Howard RD (1974) The influence of sexual selection and interspecific competition on mockingbird song (Mimus polyglottos). Evolution 28:428-438

Johnson S (2006) Do American Robins acquire songs by both imitating and inventing? Wilson J Ornithol 118:341-352

Kiefer S, Sommer C, Scharff C, Kipper S, Mundry R (2009) Tuning towards tomorrow? Common nightingales Luscinia megarhynchos change and increase their song repertoires from the first to the second breeding season. J Avian Biol 40:231-236

Kipper S, Kiefer S (2010) Age-related changes in birds' singing styles: on fresh tunes and fading voices? Adv Stud Behav 41:77-118

Kipper S, Mundry R, Hultsch H, Todt D (2004) Long-term persistence of song performance rules in nightingales (Luscinia megarhynchos): a longitudinal field study on repertoire size and composition. Behaviour 141:371-390

Krebs J, Ashcroft R, Webber M (1978) Song repertoires and territory defence in the great tit. Nature 271:539-542

Kroodsma DE (1982) Learning and the ontogeny of sound signals in birds. In: Kroodsma DE, Miller EH (eds) Acoustic communication in birds, vol 2, song learning and its consequences. Academic Press, Boston, pp 1-24

Kroodsma DE, Liu W, Goodwin E, Bedell P (1999) The ecology of song improvisation as illustrated by North American Sedge Wrens. Auk 116:373-386

Lampe HM, Saetre G (1995) Female pied flycatchers prefer males with larger song repertoires. Proc R Soc B 262:163-167

Leitner S, Voigt C, Gahr M (2001) Seasonal changes in the song pattern of the non-domesticated island canary (Serinus canaria), a field study. Behaviour 138:885-904

Lynch A (1996) The population memetics of birdsong. In: Kroodsma DE, Miller EH (eds) Ecology and evolution of acoustic communication in birds. Comstock Publishing Associates, New York, pp 181-197

Marler P (1970) A comparative approach to vocal learning: song development in white-crowned sparrows. Journal of Comparative and Physiological Psychology Monograph 71:1-25

Marler P, Peters S (1981) Sparrows learn adult song and more from memory. Science 213:780-782

Marler P, Peters S (1982) Subsong and plastic song: their role in the vocal learning process. In: Kroodsma DE, Miller EH (eds) Acoustic communication in birds, vol 2, song learning and its consequences. Academic Press, Boston, pp 25-50

Marler P, Mundinger P, Waser MS, Lutjen A (1972) Effects of acoustical stimulation and deprivation on song development in red-winged blackbirds (Agelaius phoeniceus). Anim Behav 20:586-606

McGregor PK, Krebs JR (1982) Mating and song types in the great tit. Nature 297:60-61

Molles LE, Vehrencamp SL (1999) Repertoire size, repertoire overlap, and singing modes in the Banded Wren (Thryothorus pleurostictus). Auk 116:677-689

Mountjoy DJ, Lemon RE (1995) Extended song learning in wild European starlings. Anim Behav 49:357-366
Nelson DA (1992) Song overproduction and selective attrition lead to song sharing in the field sparrow (Spizella pusilla). Behav Ecol Sociobiol 30:415-424

Nicholson JS, Buchanan KL, Marshall RC, Catchpole CK (2007) Song sharing and repertoire size in the sedge warbler, Acrocephalus schoenobaenus: changes within and between years. Anim Behav 74:1585-1592

Nordby JC, Campbell SE, Beecher MD (2001) Late song learning in song sparrows. Anim Behav 61:835-846

Nottebohm F (2004) The road we travelled: discovery, choreography, and significance of brain replaceable neurons. Ann NY Acad Sci 1016:628-658

Nottebohm F, Nottebohm ME, Crane L (1986) Development and seasonal changes in canary song and their relation to changes in the anatomy of song-control nuclei. Behav Neural Biol 46:445-471

Nowicki S, Nelson DA (1990) Defining natural categories in acoustic signals: comparison of three methods applied to 'chick-a-dee' call notes. Ethology 86:89-101

Payne RB (1996) Song traditions in indigo buntings: origin, improvisation, dispersal, and extinction in cultural evolution. In: Kroodsma DE, Miller EH (eds) Ecology and evolution of acoustic communication in birds. Comstock Publishing Associates, New York, pp 198-220

Payne RB, Payne LL (1997) Field observations, experimental design, and the time and place of learning bird songs. In: Snowdon CT, Hausberger M (eds) Social influences on vocal development. Cambridge University Press, Cambridge, pp 57-84

Pfaff JA, Zanette L, MacDougall-Shackleton SA, MacDougallShackleton EA (2007) Song repertoire size varies with HVC volume and is indicative of male quality in song sparrows (Melospiza melodia). Proc R Soc B 274:2035-2040

Rassmussen R, Dabelsteen T (2002) Song repertoires and repertoire sharing in a local group of blackbirds. Bioacoustics 13:63-76

R Development Core Team (2012) R: a language and environment for statistical computing. R Foundation for Statistical Computing, Vienna. ISBN: 3-900051-07-0. http://www.R-project.org/

Saranathan V, Hamilton D, Powell GVN, Kroodsma DE, Prum RO (2007) Genetic evidence supports song learning in the threewattled bellbird Procnias tricarunculata (Cotingidae). Mol Ecol 16:3689-3702

Searcy WA (1992) Song repertoire and mate choice in birds. Am Zool 32:71-80

Searcy WA, Andersson M (1986) Sexual selection and the evolution of song. Annu Rev Ecol Syst 17:507-533

Searcy WA, Beecher MD (2009) Song as an aggressive signal in songbirds. Anim Behav 78:1282-1292

Sorjonen J (1987) Temporal and spatial differences in traditions and repertoires in the song of the thrush nightingale (Luscinia luscinia). Behaviour 102:196-212

Stiles FG, Skutch AF (1989) A guide to the birds of Costa Rica. Cornell University Press, Ithaca

Stutchbury BJM, Morton ES, Piper WH (1998) Extra-pair mating system of a synchronously breeding tropical songbird. J Avian Biol 29:72-78

Sung H, Park S (2005) Explaining avian vocalizations: a review of song learning and song communication in male-male interactions. Integrative Biosciences 9:47-55

Todt D, Geberzahn N (2003) Age-dependent effects of song exposure: song crystallization sets a boundary between fast and delayed vocal imitation. Anim Behav 65:971-979

Vargas-Castro LE (2015) Spatial pattern of syllable sharing in whitethroated thrushes: implications for song learning and dispersal behaviours. Behaviour 152:775-795 
Vargas-Castro LE, Sánchez NV, Barrantes G (2012) Repertoire size and syllable sharing in the song of the clay-colored Thrush (Turdus grayi). Wilson J Ornithol 124:446-453
Zar JH (1996) Biostatistical analysis, 3rd edn. Prentice Hall, New Jersey 